ORIGINAL ARTICLE

\title{
Inverse correlation between high level expression of cyclin $E$ and proliferation index in transitional cell carcinoma of the bladder
}

\author{
A A Khan, P D Abel, K S Chaudhary, Z Gulzar, G W H Stamp, E-N Lalani
}

J Clin Pathol: Mol Pathol 2003;56:353-361

See end of article for authors' affiliations

Correspondence to: Professor E-N Lalani, Department of Histopathology, Division of Investigative Sciences, Faculty of Medicine, Imperial College, Hammersmith Campus, Du Cane Road, London W12 ONN, UK; e.lalani@ imperial.ac.uk

Accepted for publication 22 August 2003
Background/Aims: Overexpression of the G1 cyclins, D1 and E, and/or downregulation of p27 ${ }^{\text {Kip } 1}$ allow uncontrolled tumour cell proliferation. This study investigated the relation between these three cell cycle proteins and tumour proliferation in bladder cancer.

Method: Nuclear expression of cyclin D1, cyclin E, and p $27^{\text {Kip } 1}$ was determined immunohistochemically in 52 primary transitional cell carcinomas, and the Ki-67 proliferation marker was also assessed. For each protein, the percentage of positive tumour cell nuclei was determined and analysed as a continuous variable.

Results: Advancing tumour grade and pathological stage were accompanied by increasing proliferation indices, but decreasing $\mathrm{p} 27^{\mathrm{Kipl}}$ and cyclin D1 expression, with no significant change in cyclin E expression. Overall, cyclin D1 and E expression did not correlate with proliferation. However, in cyclin D1 overexpressing tumours ( $\geqslant 5 \%$ nuclei positive), the level of cyclin D1 expression positively correlated with proliferation. The correlation between cyclin $\mathrm{E}$ expression and proliferation changed from positive to negative with increasing levels of cyclin $\mathrm{E}$ expression, accompanied by a coordinate increase in $\mathrm{p} 27^{\text {Kip } 1}$ expression. Overall, there was an inverse association between p27 Kipl expression and proliferation. However, a subset of tumours displayed high proliferation indices despite high p27 ${ }^{\text {Kipl } 1}$ expression. The G1 cyclin index (sum of the level of expression of cyclins DI and E) correlated positively with proliferation in superficial but not muscle invasive tumours. This correlation was stronger when the G1 cyclin index was adjusted for $\mathrm{p} 27^{\mathrm{Kipl}}$ expression.

Conclusion: These findings support a role for these proteins in the proliferation, differentiation, and progression of bladder transitional cell carcinomas.
M ultiple positive and negative regulators control progression through the cell cycle. The cyclins are a group of positive regulatory proteins, which in association with their catalytic subunits, the cyclin dependent kinases (CDKs), mediate important cell cycle transitions. ${ }^{1-3}$ The activity of the cyclin-CDK complexes is negatively regulated by the CDK inhibitors. ${ }^{1-3}$ At the GI-S boundary, these proteins control entry of the cell into its DNA replicative $S$ phase. After passing through the restriction point in late Gl, cells are generally committed to completing at least one round of the cell cycle. At this point, the Gl-S transition is tightly regulated to ensure that damaged DNA is not replicated. Altered regulation of this crucial checkpoint can result in uncontrolled cell proliferation and the transmission of damaged DNA to daughter cells. ${ }^{2}$ Not surprisingly, regulatory defects involving the Gl-S checkpoint have been observed in many human cancers. ${ }^{1-3}$

"The cyclin dependent kinase (CDK) inhibitor, p27"Kip1 blocks the activity of cyclin D1-CDK4/6 and cyclin ECDK2, and is an important negative regulator of the G1-S transition"

Cyclins DI and E are important positive regulators of the Gl-S transition. Cyclin Dl is expressed in early Gl in response to mitogenic signals and is primarily involved in $\mathrm{Gl}$ phase progression. ${ }^{3}$ Its expression is maximal in mid-Gl phase. Cyclin E is expressed in late Gl and facilitates $\mathrm{S}$ phase entry. ${ }^{3}$ Both Gl cyclins form active complexes with their respective CDKs (cyclin D1, CDK4/6; cyclin E, CDK2) to phosphorylate three pocket proteins of the retinoblastoma family, pRB, p107, and p130, which then release the transcription factors required for $\mathrm{S}$ phase entry. ${ }^{4}$ In vitro, forced overexpression of cyclin Dl and cyclin E accelerates the Gl-S transition, resulting in a shortened Gl phase and reduced growth factor requirement. ${ }^{5}$ Although both cyclin D I and $\mathrm{E}$ have a rate limiting role in Gl-S progression, only cyclin $\mathrm{E}$ has been shown to be essential for this process. ${ }^{67}$ Furthermore, cyclin Dl is dependent on wild-type pRb for its role in cell cycle progression, ${ }^{89}$ whereas cyclin E can function in RB negative cells. ${ }^{6}{ }^{10}$ Forced overexpression of Gl cyclins can overcome control of the Gl-S checkpoint, leading to unrestrained proliferation, so that these proteins are thought to have oncogenic potential. Overexpression of cyclins Dl and E, as a result of gene amplification or altered posttranscriptional regulation, has been observed in many human cancers, and generally correlates with advancing degree of malignancy and poor prognosis. ${ }^{1-3} 1112$

In contrast, the CDK inhibitor, p2 $7^{\text {Kipl }}$ blocks the activity of cyclin D1-CDK4/6 and cyclin E-CDK2, and is an important negative regulator of the Gl-S transition. ${ }^{1-3}$ The concentration of $\mathrm{p} 27^{\mathrm{Kipl}}$ is normally high in resting cells, but declines in response to proliferative stimuli. ${ }^{13}$ Forced overexpression of $\mathrm{p} 27^{\mathrm{Kipl}}$ in cell lines leads to Gl arrest. ${ }^{14}$ Furthermore, antisense inhibition of $\mathrm{p} 27^{\mathrm{Kipl}}$ protein synthesis in proliferating

Abbreviations: CDK, cyclin dependent kinase; PBS, phosphate buffered saline; $\mathrm{PRb}$, retinoblastoma protein; TCC, transitional cell carcinoma of the bladder 
cells blocks re-entry into the resting or G0 phase of the cell cycle. ${ }^{15}$ As a negative regulator of cell cycle progression, p27 $7^{\text {Kipl }}$ is also considered to be a tumour suppressor. ${ }^{1}$ Progressive downregulation of $\mathrm{p} 27^{\mathrm{Kipl}}$ is a common finding in different types of cancer, and is associated with advanced disease and reduced survival. ${ }^{1-3}{ }^{16}$ Post-translational mechanisms, mainly increased ubiquitin mediated proteolysis, account for reduced concentrations of $\mathrm{p} 27^{\mathrm{Kipl}}$, because it is rarely mutated in human cancers. ${ }^{16}$

In transitional cell carcinoma of the bladder (TCC), cyclin Dl overexpression correlates with low tumour grade and stage, and has been shown to be a predictor of early recurrence. ${ }^{17-20}$ Loss of $\mathrm{p} 27^{\text {Kipl }}$ expression in superficial TCCs has been correlated with tumour grade and reduced survival. ${ }^{21}$ More recently, it has been reported that reduced expression of both cyclin E and p $27^{\text {Kip } 1}$ predicts poor survival in TCC. ${ }^{22}$ However, these three cell cycle regulators have not been studied concurrently in bladder cancer and their association with the proliferation index has not been explored.

In our present study, we determined the nuclear expression of cyclin D1, cyclin E, and $\mathrm{p} 27^{\mathrm{Kipl}}$ in a series of 52 primary TCCs. The results were correlated with tumour grade and pathological stage. In addition, we studied the relation between the expression of these proteins and the proliferation index, as assessed by Ki-67 expression. We observed a paradoxical, negative correlation between the level of cyclin E expression and the proliferation index in tumours that displayed a high level of cyclin E expression ( $\geqslant 30 \%$ nuclei positive). In contrast, the level of cyclin E expression was positively correlated with the proliferation index in low expressors of cyclin E $(<30 \%)$. We propose an explanation for these findings and discuss their implications.

\section{MATERIALS AND METHODS \\ Patients and tissue samples}

Formalin fixed, paraffin wax embedded tissue blocks from 52 patients with a confirmed diagnosis of primary TCC of the bladder were obtained from the department of histopathology and the human biomaterials resource centre of the Imperial College School of Medicine, Hammersmith Hospital Campus, London, UK. The median age of the patients was 71 years (range, 35-95). Forty six were men and six were women. Tumour specimens were obtained from 34 transurethral resections, six cystectomies, and 12 biopsies (transurethral resection or cold cup). In all cases, only samples in which the presence of detrusor muscle was identified histologically were selected to ensure accuracy in reflecting pT category. None of the patients had received irradiation or chemotherapy. Seven tumours were classified according to the World Health Organisation ${ }^{23}$ as well differentiated (grade 1), 26 as moderately differentiated (grade 2), and 19 as poorly differentiated (grade 3 ). In accordance with the classification of the American Joint Committee on Cancer, ${ }^{24}$ there were 14 pTa, 19 pT1, seven pT2, and 12 pT3/4 tumours. In 29 tumours, a papillary phenotype was identified.

\section{Immunohistochemistry}

Well characterised, mouse monoclonal antibodies against Ki67 antigen (MIB-1; Immunotech, Marseille, France), p2 $7^{\text {Kip } 1}$ (Transduction Laboratories, Lexington, Kentucky, USA), and cyclin E (HE12; Santa Cruz Biotechnology, Santa Cruz, California, USA), each at a $1 / 400$ dilution, and cyclin Dl (P2DllF11; Novocastra Laboratories, Newcastle upon Tyne, $\mathrm{UK})$, at a $1 / 20$ dilution, were used. Serial sections $(5 \mu \mathrm{m}$ thick) were mounted on poly-L-lysine coated slides. Sections were dewaxed, rehydrated, and washed in phosphate buffered saline (PBS; pH 7.2). To enhance antigen exposure, slides were immersed in prewarmed $0.01 \mathrm{M}$ citrate buffer
(pH 6.0) and microwaved at $750 \mathrm{~W}$ (Philips M902), three times for five minutes each. Sections were then allowed to cool for 20 minutes. Endogenous peroxidase activity was blocked with $0.3 \% \mathrm{vol} / \mathrm{vol} \mathrm{H}_{2} \mathrm{O}_{2}$ for 30 minutes. Sections were washed in PBS and incubated with $10 \%$ normal rabbit serum (Dako, Glostrup, Denmark) for 30 minutes to block nonspecific binding sites. This was followed by overnight incubation with each primary antibody at $4^{\circ} \mathrm{C}$. Secondary antibody (biotinylated rabbit antimouse immunoglobulin; 1/ 200 dilution; Dako) was applied for 45 minutes at room temperature. After sections were washed in PBS, avidinbiotin-horseradish peroxidase complexes (1/100 dilution; Dako) were applied for 30 minutes. 3,3'-Diaminobenzidine solution (0.05\% wt/vol; Sigma, Poole, Dorset, UK) was used as the final chromogen and sections were counterstained with Cole's haematoxylin (Pioneer Research Chemicals, Essex, UK). Sections in which the primary antibody was replaced by PBS were used as negative controls. Sections with stromal lymphoid follicles clearly displaying an inverse relation between $\mathrm{p} 27^{\mathrm{Kipl}}$ and Ki-67 expression in lymphocytes were included as positive controls for p2 $7^{\text {Kipl }}$ and Ki- 67. In addition, stromal or peritumoural lymphocytes were present in most cases and served as internal controls for p2 $7^{\text {Kipl }}$ and Ki-67. As previously reported by Dutta et al, ${ }^{25}$ we consistently found endothelial cytoplasmic crossreactivity with the HEl2 anti-cyclin E antibody used. Whereas they had suggested that this property of the HEl2 antibody could be used to assess tumour vasculature, we found it to be a consistent and useful positive internal control for cyclin E immunoreactivity. A breast tumour specimen with known cyclin Dl and E expression was used as a positive control for cyclins Dl and E.

\section{Evaluation of immunostaining}

Slides were reviewed independently by three investigators, without knowledge of the clinical data (AAK, KSC, ENL). Interobserver discrepancies were resolved using a double headed microscope. Only nuclear expression was recorded. The number of distinctly positive tumour cell nuclei was counted under high power $(\times 400)$ using a $10 \times 10$ eyepiece grid. In total, 1000 tumour cells were assessed. The number of positive nuclei was expressed as a percentage of all tumour cell nuclei counted. For Ki-67, p2 $7^{\text {Kipl }}$, and cyclin E, a single case for each antibody was excluded from the final analysis because of inadequate staining.

\section{Statistical analysis}

Individual staining indices (percentage of nuclei positive) were analysed as continuous variables. Cut off points for high versus low expression, based on median levels of expression, were included when appropriate. The Mann-Whitney U and Kruskall-Wallis tests were used for comparing two and three different groups, respectively. Correlations between variables were assessed by Spearman's rank correlation test $\left(r_{s}=\right.$ correlation coefficient). Multiple logistic regression was used to assess which independent variables were most strongly associated with a dichotomised dependent variable. All $p$ values were two tailed and considered significant when $\leqslant 0.05$. Statistical analyses were performed on Stata 6.0 (Stata Corporation, College Station, Texas, USA).

\section{RESULTS}

Expression of cyclin D 1, cyclin E, p2 $7^{\mathrm{Kip} 1}$, and Ki-67 Figures 1 and 2 show typical examples of the immunohistochemical expression of cyclin D1, cyclin E, p2 $7^{\mathrm{Kipl}}$, and Ki67 in representative TCCs. The criteria for scoring were based on previous experience from our group, in addition to review of literature. Nuclear expression of cyclin Dl ranged from $0 \%$ to $82.6 \%$ of tumour cells. Less than $5 \%, 5-30 \%$, and $>30 \%$ 

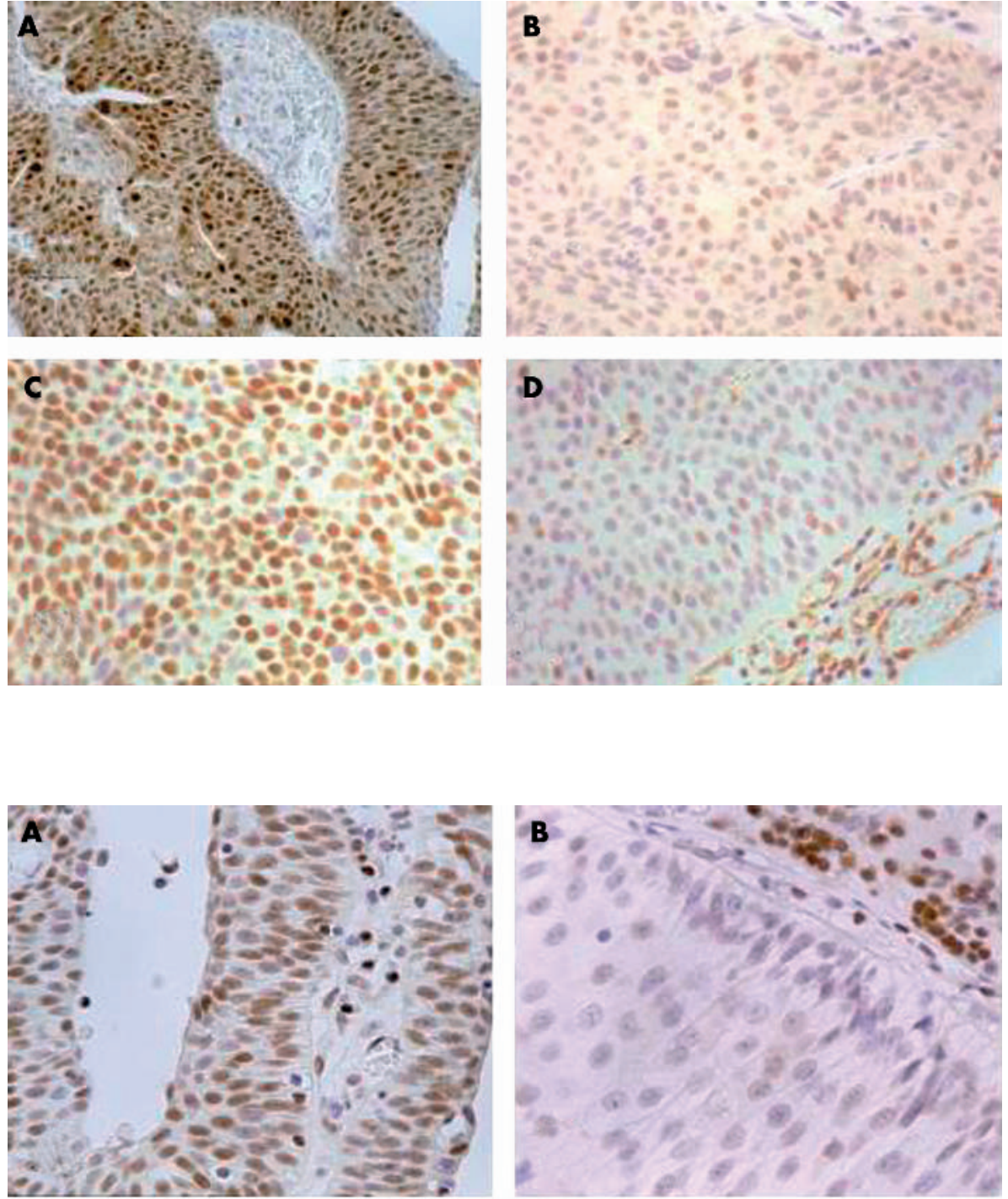

Figure 2 Immunohistochemical staining of representative bladder transitional cell carcinomas with mouse monoclonal antibodies against $\mathrm{p} 27^{\mathrm{Kip} 1}$ and Ki-67 (Mib1). (A) Strong nuclear expression of $\mathrm{p} 27^{\mathrm{Kipl}}$ in a grade 1 , papillary fumour. (B) No nuclear expression of $\mathrm{p} 27^{\mathrm{Kipl}}$ in a grade 2, muscle invasive tumour, showing strong staining of stromal lymphocytes. (C) Strong nuclear expression of $\mathrm{Ki}-67$ in a grade 3, muscle invasive tumour. (D) Low nuclear expression of $\mathrm{Ki}-67$ in a grade 1, papillary tumour (A-D: original magnification, $\times 400$ ).
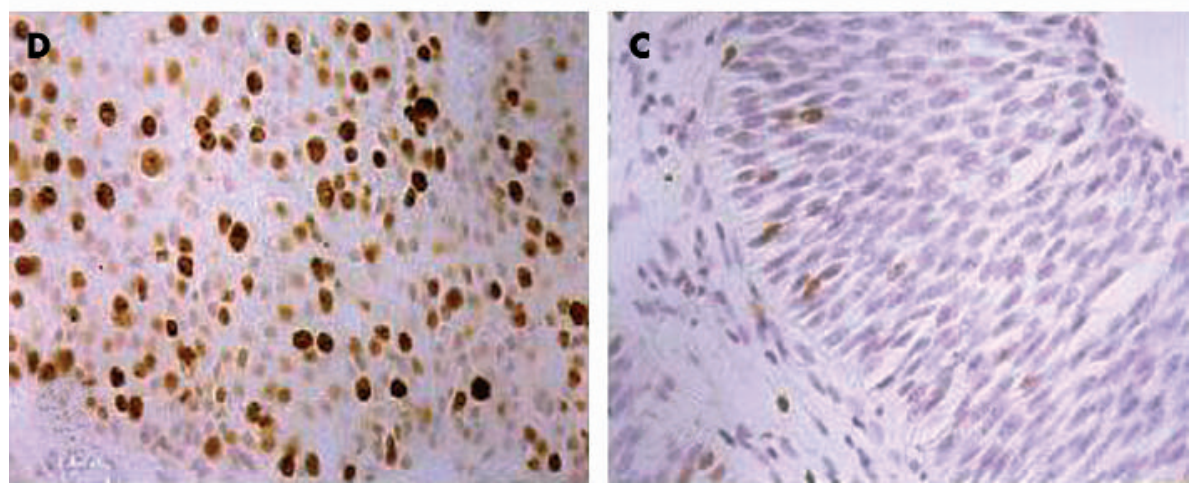

nuclear expression of cyclin D1 was seen in 31, 13, and eight of the 52 cases, respectively. Six cases had $>50 \%$ expression.

Cyclin E expression ranged from $0 \%$ to $78.1 \%$ in the tumour cells. Less than 5\%, 5-30\%, and > 30\% cyclin E expression was seen in 10, 16, and 25 of 51 tumours, respectively. In 14 tumours $>50 \%$ of nuclei were positive.

p $27^{\text {Kipl }}$ nuclear reactivity ranged from $0 \%$ to $67.4 \%$ in the tumour cells. Less than $30 \%, 30-50 \%$, and $>50 \%$ p $27^{\text {Kip } 1}$ expression was found in 29 , nine, and 13 of 51 cases, respectively.

Ki-67 protein expression ranged from $0.1 \%$ to $99.0 \%$ in the tumour cells. Less than $20 \%, 20-50 \%$, and $>50 \%$ tumour cell nuclei were Ki-67 positive in 29,17 , and five of 51 cases, respectively.

\section{Combined alterations in cell cycle protein expression} Low expression of $\mathrm{p} 27^{\mathrm{Kipl}}(<30 \%$ nuclei positive) was seen in 29 of 51 cases, whereas cyclins Dl and E were overexpressed $(\geqslant 5 \%$ and $\geqslant 30 \%$ nuclei positive, respectively) in 21 of 52 and 25 of 51 of all cases, respectively. Overexpression of one or both cyclins was seen in 33 of 50 tumours. Cyclins Dl and E were co-overexpressed in 11 cases. In 22 tumours, a single Gl cyclin was 
overexpressed: cyclin Dl in seven and cyclin E in 15. The most frequent combination was that of low cyclin D1, low cyclin E, and low p27 $7^{\mathrm{Kipl}}$ expression, which was seen in 12 of 50 cases. The combination closest to a normal profile-low cyclin D1 and E expression but high p2 $7^{\text {Kipl }}$ expression-was present in only four of 50 cases. Five of 50 cases displayed overexpression of both cyclins $\mathrm{Dl}$ and $\mathrm{E}$, in addition to downregulation of $\mathrm{p} 27^{\mathrm{Kipl}}$.

\section{Correlation between expression of cell cycle proteins, proliferation index, and histopathological variables}

The proliferation index (as determined by Ki-67 expression) increased with increasing tumour grade $(p=0.012)$ and pathological stage, and was significantly higher in muscle invasive ( $\geqslant$ pT2) and non-papillary tumours than in their superficial and papillary counterparts $(p=0.002$ and 0.03 , respectively; table 1 ). In contrast, $\mathrm{p} 27^{\mathrm{Kip} 1}$ and cyclin Dl expression decreased with increasing grade and depth of tumour invasion, and were significantly higher in superficial tumours than in muscle invasive ones ( $p=0.047$ and 0.008 , respectively). These correlations were notably more significant for cyclin D1 than for p $27^{\mathrm{Kip} 1}$. Cyclin Dl was also strongly associated with papillary morphology $(p<0.0001)$, whereas $p 27^{\text {Kipl }}$ was not $(p=0.69)$. Although a modest decrease in the level of expression of cyclin E was seen with increasing grade and depth of tumour invasion, these differences were not significant. There was also no association between cyclin E expression and papillary morphology $(p=0.96)$. We also analysed levels of cyclin D1, cyclin E, p2 $7^{\text {Kipl }}$, and Ki-67 expression together as continuous variables using multiple logistic regression, with muscle invasion (presence versus absence) as a dichotomised outcome variable. Only proliferation index (Ki-67 expression) and cyclin Dl expression were found to be significantly associated with the presence or absence of muscle invasion in this analysis $(\mathrm{p}=0.015$ and 0.045 , respectively).

\section{Correlation between expression of cell cycle proteins} and proliferation index

Overall, the level of expression of cyclins Dl and E did not correlate with the proliferation index $\left(r_{s}=-0.04, \mathrm{p}=0.8\right.$, fig 3A; and $r_{s}=0.21, p=0.15$, fig 3C; respectively). However, when low expressors of cyclin Dl $(<5 \%$ nuclei positive, $\mathrm{n}=31$ ) were excluded, we saw a significant positive correlation between cyclin Dl expression and proliferation index $\left(r_{s}=0.58, \mathrm{p}=0.008, \mathrm{n}=20\right.$; fig $\left.3 \mathrm{~B}\right)$.

We next evaluated the relation between cyclin E expression and the proliferation index in high expressors of cyclin $\mathrm{E}$ $(\geqslant 30 \%$ nuclei positive, $\mathrm{n}=25)$ versus low expressors $(<30 \%$ nuclei positive, $\mathrm{n}=25)$. Paradoxically, high expressors of cyclin E displayed a significant negative correlation between the level of cyclin E expression and the proliferation index $\left(r_{s}=-0.68, \mathrm{p}=0.002\right.$; fig 3D). In contrast, this association was reversed in low expressors of cyclin $\mathrm{E}$ $\left(r_{s}=0.56, \mathrm{p}=0.004\right.$; fig $\left.3 \mathrm{E}\right)$. To determine the level of cyclin E expression at which this correlation changed from positive to negative, the slope of the regression line for each successive $20 \%$ increase in the level of cyclin E expression is shown (fig 3F). The switch from a positive to a negative association occurred at $>40 \%$ expression of cyclin E.

To explain these opposing relations, we examined the expression of $\mathrm{p} 27^{\mathrm{Kipl}}$, a major inhibitor of cyclin E associated kinase activity. We found that high expressors of cyclin E $(\geqslant 30 \%)$ compared with low expressors had significantly higher levels of $\mathrm{p} 27^{\mathrm{Kipl}}$ expression (mean, 35.0\%; SEM, $4.5 \%$ versus mean, 20.6\%; SEM, 4.0\%; $\mathrm{p}=0.025$ ). Furthermore, although there was an overall positive correlation between p2 $7^{\text {Kipl }}$ and cyclin E expression $\left(r_{s}=0.32, \mathrm{p}=0.02\right.$; fig $\left.4 \mathrm{~A}\right)$, we observed a difference in this association between high and low expressors of cyclin E. High expressors of cyclin E

Table 1 Nuclear expression of Ki-67, p2 $7^{\mathrm{Kip} 1}$, cyclin D1, and cyclin E in transitional cell carcinoma of the bladder in relation to patient and histopathological variables

\begin{tabular}{|c|c|c|c|c|}
\hline & Ki-67 & p27Kip1 & Cyclin D1 & Cyclin E \\
\hline All patients & $24.3(3.2 ; 51)$ & $27.7(3.1 ; 51)$ & $14.9(3.2 ; 52)$ & $31.4(3.3 ; 51)$ \\
\hline \multicolumn{5}{|l|}{ Age (years) } \\
\hline$<65$ & $38.1(8.9 ; 14)$ & $19.0(6.3 ; 14)$ & $7.7(5.1 ; 14)$ & $23.4(5.5 ; 14)$ \\
\hline$\geqslant 65$ & $19.0(2.3 ; 37)$ & $31.1(3.5 ; 37)$ & $17.6(3.9 ; 38)$ & $34.4(4.0 ; 37)$ \\
\hline $\mathrm{p}$ Value & 0.12 & 0.09 & 0.06 & 0.15 \\
\hline \multicolumn{5}{|l|}{ Sex } \\
\hline Male & $23.4(3.4 ; 45)$ & $28.0(3.4 ; 45)$ & $16.3(3.6 ; 46)$ & $32.6(3.6 ; 45)$ \\
\hline Female & $30.5(7.8 ; 6)$ & $25.9(6.6 ; 6)$ & $4.7(4.7 ; 6)$ & $21.9(7.2 ; 6)$ \\
\hline $\mathrm{p}$ Value & 0.18 & 0.88 & 0.18 & 0.41 \\
\hline \multicolumn{5}{|l|}{ Papillary morphology } \\
\hline Present & $16.6(2.0 ; 28)$ & $28.5(4.0 ; 28)$ & $26.3(4.8 ; 29)$ & $31.7(4.6 ; 28)$ \\
\hline Absent & $33.6(6.0 ; 23)$ & $26.8(5.0 ; 23)$ & $0.6(0.4 ; 23)$ & $31.0(4.9 ; 23)$ \\
\hline $\mathrm{p}$ Value & 0.031 & 0.69 & $<0.0001$ & 0.962 \\
\hline \multicolumn{5}{|l|}{ Tumour grade } \\
\hline G1 & $12.5(3.9 ; 7)$ & $45.7(7.9 ; 6)$ & $32.2(12.7 ; 7)$ & $45.2(11.7 ; 7)$ \\
\hline G2 & $17.2(2.2 ; 25)$ & $27.8(4.1 ; 26)$ & $18.9(4.6 ; 26)$ & $26.4(4.3 ; 25)$ \\
\hline G3 & $37.8(6.8 ; 19)$ & $22.1(5.2 ; 19)$ & $3.1(2.5 ; 19)$ & $32.9(5.1 ; 19)$ \\
\hline $\mathrm{p}$ Value & $0.012^{*}$ & $0.08^{*}$ & $0.006^{*}$ & $0.207^{*}$ \\
\hline \multicolumn{5}{|l|}{ Pathological stage } \\
\hline pTa & $13.5(2.7 ; 14)$ & $34.2(6.6 ; 14)$ & $25.2(8.1 ; 14)$ & $32.9(6.7 ; 14)$ \\
\hline pTl & $17.5(2.7 ; 18)$ & $30.4(4.8 ; 18)$ & $16.2(4.9 ; 19)$ & $34.5(6.7 ; 18)$ \\
\hline рT2 & $34.9(11.0 ; 7)$ & $30.7(9.5 ; 7)$ & $14.3(9.3 ; 7)$ & $25.3(6.5 ; 7)$ \\
\hline рТ3/4 & $40.6(8.8 ; 12)$ & $14.6(4.6 ; 12)$ & $1.3(1.1 ; 12)$ & $28.6(5.1 ; 12)$ \\
\hline \multicolumn{5}{|l|}{ p Value } \\
\hline Invasive ( $\geqslant p T 1$ ) & $28.3(4.0 ; 37)$ & $25.3(3.4 ; 37)$ & $11.1(3.1 ; 38)$ & $30.8(3.8 ; 37)$ \\
\hline $\mathrm{p}$ Value & $0.03 \dagger$ & $0.17 \dagger$ & $0.09 \dagger$ & $0.87 \dagger$ \\
\hline Superficial ( $\leqslant \mathrm{pTl}$ ) & $15.8(1.9 ; 32)$ & $32.1(3.9 ; 32)$ & $20.0(4.4 ; 33)$ & $33.8(4.7 ; 32)$ \\
\hline Muscle invasive ( $\geqslant p T 2$ ) & $38.5(6.7 ; 19)$ & $20.5(4.8 ; 19)$ & $6.1(3.6 ; 19)$ & $27.4(3.9 ; 19)$ \\
\hline $\mathrm{p}$ Value & 0.002 & 0.047 & 0.008 & 0.54 \\
\hline
\end{tabular}





Figure 3 Scatter diagrams of cyclin D1 or cyclin E versus $\mathrm{Ki}-67$ expression (percentage of nuclei positive). (A) All cases together, showing no correlation between cyclin D1 and $\mathrm{Ki}-67$ expression; (B) high expressors of cyclin DI ( $\geqslant 5 \%$ nuclei positive), showing a positive correlation; (C) all cases together, showing no correlation between cyclin $\mathrm{E}$ and $\mathrm{Ki}-67$ expression (D) high expressors of cyclin $\mathrm{E}(\geqslant 30 \%$ nuclei positive), showing a negative correlation; and (E) low expressors of cyclin $E(<30 \%$ nuclei positive),

showing a positive correlation $\left(r_{s}\right.$ Spearman's rank correlation coefficient). Filled and unfilled circles represent superficial and muscle
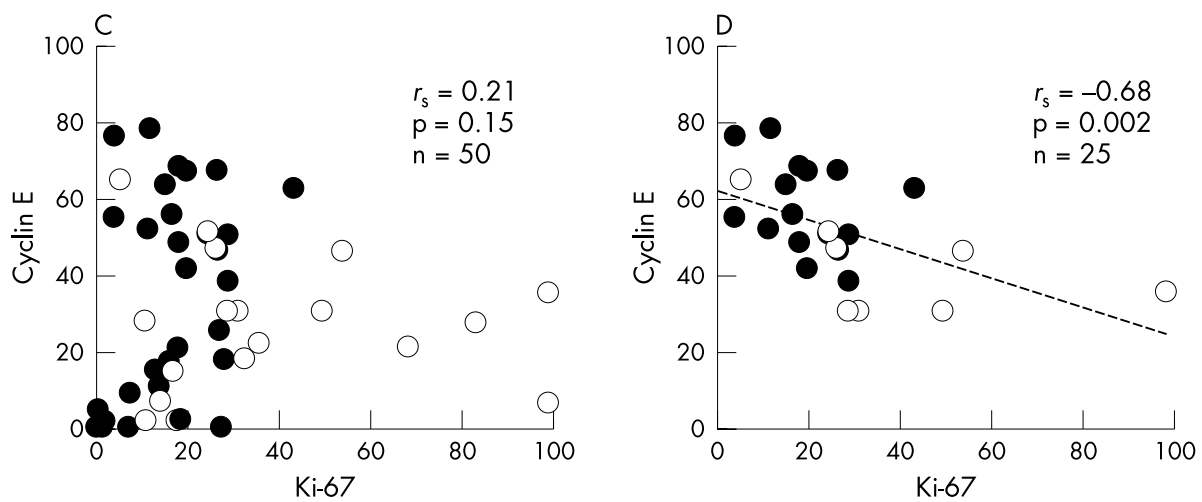
invasive tumours, respectively. (F) shows the slope of the regression line for each successive $20 \%$ increase in cyclin E expression. The relation between cyclin $\mathrm{E}$ expression and the proliferation index changed from positive to negative at $>40 \%$ cyclin $E$ expression.


displayed a positive correlation between $\mathrm{p} 27^{\mathrm{Kipl}}$ and cyclin $\mathrm{E}$ expression, approaching significance $\left(r_{s}=0.38, \mathrm{p}=0.06\right)$, whereas in low expressors of cyclin E, there was no significant correlation $\left(r_{s}=-0.24, \mathrm{p}=0.24\right)$. More importantly, as shown in fig $4 \mathrm{~B}$, there was a pronounced increase in the slope of the regression line coincident with the $>40 \%$ level of cyclin E expression.

Because cyclin Dl is known to sequester $\mathrm{p} 27^{\mathrm{Kipl}}$, thereby decreasing the pool of $\mathrm{p} 27^{\mathrm{Kipl}}$ available for inhibition of cyclin E-CDK2 activity, it was also important to determine the level of expression of cyclin D1. However, we did not find a significant difference in its level of expression in high versus low expressors of cyclin E (mean, 18.4\%; SEM, 5.6\% versus mean, $11.5 \%$; SEM, $3.4 \%$, respectively; $p=0.599$ ).

An overall inverse correlation between p2 $7^{\mathrm{Kipl}}$ expression and proliferation index was found $\left(r_{s}=-0.36, \mathrm{p}=0.01\right.$; fig 4C). However, eight tumours displayed high proliferation indices $(\geqslant 20 \%)$, despite high level expression of $\mathrm{p} 27^{\text {Kipl }}$ $(\geqslant 30 \%)$. Each of these showed overexpression of one or both cyclins (Dl and/or E). Four of these were poorly differentiated and muscle invasive tumours.
When superficial TCCs were compared with muscle invasive tumours, we found weak positive correlations between the proliferation index and expression levels of both cyclins Dl and E in superficial but not in muscle invasive tumours $\left(r_{s}=0.37, \mathrm{p}=0.04\right.$ and $r_{s}=0.33, \mathrm{p}=0.07$ versus $r_{s}=-0.29, \mathrm{p}=0.22$ and $r_{s}=0.04, \mathrm{p}=0.87$, respectively). Although there was no significant correlation between the level of $\mathrm{p} 27^{\mathrm{Kipl}}$ expression and the proliferation index among superficial tumours $\left(r_{s}=-0.29, \mathrm{p}=0.108\right)$, a corresponding negative correlation was seen in the muscle invasive group $\left(r_{s}=-0.45, \mathrm{p}=0.05\right)$.

To assess whether there were any cooperative effects of the expression of both Gl cyclins on tumour proliferation, we determined the sum of their levels of expression as a combined index of Gl cyclin expression. Although overall this index did not correlate with the proliferation index $\left(r_{s}=0.21, \mathrm{p}=0.145, \mathrm{n}=50 ;\right.$ fig 5A), there was a significant positive correlation between the proliferation index and the combined levels of expression of cyclins Dl and $\mathrm{E}$ in superficial TCCs but not in muscle invasive tumours $\left(r_{s}=0.48, \mathrm{p}=0.008\right.$ versus $r_{s}=-0.15, \mathrm{p}=0.534$; 

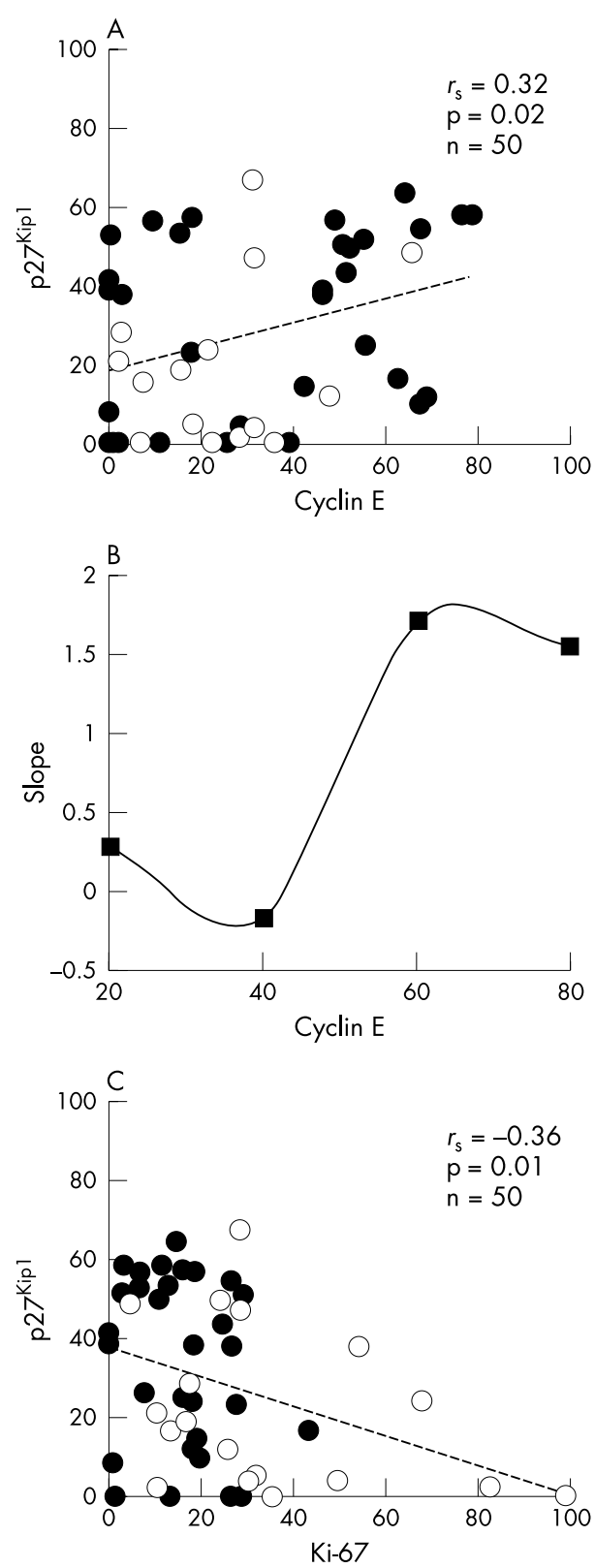

Figure 4 (A) Scatter diagram of p2 $27^{K i p l}$ versus cyclin E expression (percentage of nuclei positive), showing a weak correlation between p27 ${ }^{K i p 1}$ and cyclin E expression. (B) The slope of the regression line for each successive $20 \%$ increase in cyclin $E$ expression, showing a pronounced increase in the correlation between $p 27^{\text {Kipl }}$ and cyclin $E$ expression, coincident with a level of $>40 \%$ cyclin $\mathrm{E}$ expression. (C) Scatter diagram of $\mathrm{p} 27^{\mathrm{Kip} 1}$ versus Ki-67 expression (percentage of nuclei positive), showing a weak negative correlation between $\mathrm{p} 27^{\text {Kip }}$ and Ki-67 expression ( $r_{s}$, Spearman's rank correlation coefficient). Filled and unfilled circles represent superficial and muscle invasive tumours, respectively.

fig 5B). To account for the inhibitory effect of $\mathrm{p} 27^{\mathrm{Kipl}}$ on $\mathrm{Gl}$ cyclin activity, we simply subtracted the level of p2 $7^{\mathrm{Kipl}}$ expression from the Gl cyclin index for each tumour, yielding a composite expression index of all three cell cycle proteins. This index was significantly correlated with the proliferation index for all TCCs together $\left(r_{s}=0.40\right.$, $\mathrm{p}=0.005, \mathrm{n}=49$; fig $5 \mathrm{C}$ ), and even more strongly so in the superficial group of TCCs $\left(r_{s}=0.59, \mathrm{p}=0.001\right.$, $\mathrm{n}=30$; fig $5 \mathrm{D})$, but not in muscle invasive tumours $\left(r_{s}=0.23, \mathrm{p}=0.324\right)$.
There was no correlation between $\mathrm{p} 27^{\mathrm{Kipl}}$ and cyclin D1 expression $\left(r_{s}=0.02, \mathrm{p}=0.90\right)$, or between cyclin Dl and E expression $\left(r_{s}=0.14, \mathrm{p}=0.35\right)$. When levels of cyclin D1, cyclin E, and p $27^{\text {Kipl }}$ expression were analysed together as continuous variables using multiple logistic regression, with the proliferation index included as a dichotomised dependent variable (high versus low, at a $20 \%$ cut off), we found that only p27 $7^{\text {Kipl }}$ expression was significantly associated with the proliferation index $(\mathrm{p}=0.045)$.

\section{DISCUSSION}

Overexpression of the Gl cyclins, Dl and E, and/or downregulation of $\mathrm{p} 27^{\mathrm{Kip} 1}$ are potent mechanisms that allow tumour cells to undergo uncontrolled proliferation. ${ }^{2-4}$ In normal tissues, concentrations of $\mathrm{p} 27^{\mathrm{Kipl}}$ and Gl cyclins are closely related to cell proliferation. However, in tumours the expression is frequently deregulated relative to tumour proliferation status. $^{25}{ }^{26}$ There is also inappropriate expression relative to cell cycle phase, often leading to a disturbed order of expression. ${ }^{26}$

In our immunohistochemical study, we determined the nuclear expression of three key regulators of the Gl-S transition, cyclin D1, cyclin E, and $\mathrm{p} 27^{\mathrm{Kipl}}$, in primary TCC. The expression of these cell cycle proteins was correlated with grade, pathological stage, and the proliferation index. The inclusion of biopsied samples limited accurate classification of the pathological stage, but there was adequate tissue in all cases to classify tumour grade.

The expression of cyclin D1, cyclin E, and p2 $7^{\text {Kipl }}$ in our study was comparable to that reported previously, including the results from studies on animal models of TCC. ${ }^{17-22} 2728$ Advancing tumour grade and depth of invasion were accompanied by increasing proliferation indices but decreasing cyclin D1 and p27 Kip1 expression, whereas cyclin E expression did not change significantly, but there are conflicting reports of cyclin Dl expression in TCC. Three studies found an association between cyclin Dl overexpression and low tumour grade and/or stage, ${ }^{17} 1820$ but others have reported no relation in TCC. ${ }^{19}$ These differences may result from the different antibodies, methods, and/or cut off points used. Unlike previous reports, we decided to analyse levels of cyclin Dl expression as a continuous variable. We also found a strong association between cyclin Dl expression and papillary phenotype, as reported by others..$^{17}{ }^{20}$ Our results suggest that cyclin Dl overexpression may be an important early event in the progression of TCCs. In addition, its association with well differentiated, papillary tumours suggests that cyclin Dl may also play a role in tumour differentiation.

\section{"Our results suggest that cyclin D1 overexpression may be an important early event in the progression of transitional cell carcinomas"}

However, it is not clear whether the apparent downregulation of cyclin Dl with increasing tumour grade and stage occurs in the same TCC cells, or is the result of a clonal selection process, whereby the accumulation of other mutations (for example, RB and TP53) ( $^{29}$ possibly confers a greater growth advantage to cyclin Dl negative cells. The role of cyclin Dl as a positive regulator of cell cycle progression is dependent on the presence of wild-type $\mathrm{pRb}^{6-8}$ Moreover, $\mathrm{pRb}$ can directly induce cyclin Dl gene expression by interacting with the $\mathrm{Dl}$ promoter. ${ }^{30}$ Cyclin Dl overexpression and inactivating RB mutations have not been found concurrently in tumour cells, ${ }^{81-33}$ and are considered mutually exclusive events in TCC. ${ }^{18}$ It is likely that the apparent downregulation of cyclin Dl is a manifestation of the clonal selection hypothesis outlined above, as opposed to a decrease in cyclin Dl expression per se. Further studies are 



Figure 5 Scatter diagrams of the G1 cyclin index (sum of the levels of expression of cyclins DI and E) versus $\mathrm{Ki}-67$ expression (percentage of nuclei positive). (A) All cases together, showing no correlation between $\mathrm{G} 1$ cyclin index and $\mathrm{Ki}-67$ proliferation index. (B) Superficial tumours only, showing a positive association. (C) All cases together, with the $\mathrm{Gl}$ cyclin index adjusted for p2 $7^{\text {Kip } 1}$ expression (level of p2 $7^{\text {Kipl }}$ expression subtracted from $\mathrm{Gl}$ cyclin index), showing a positive correlation. (D) Superficial tumours
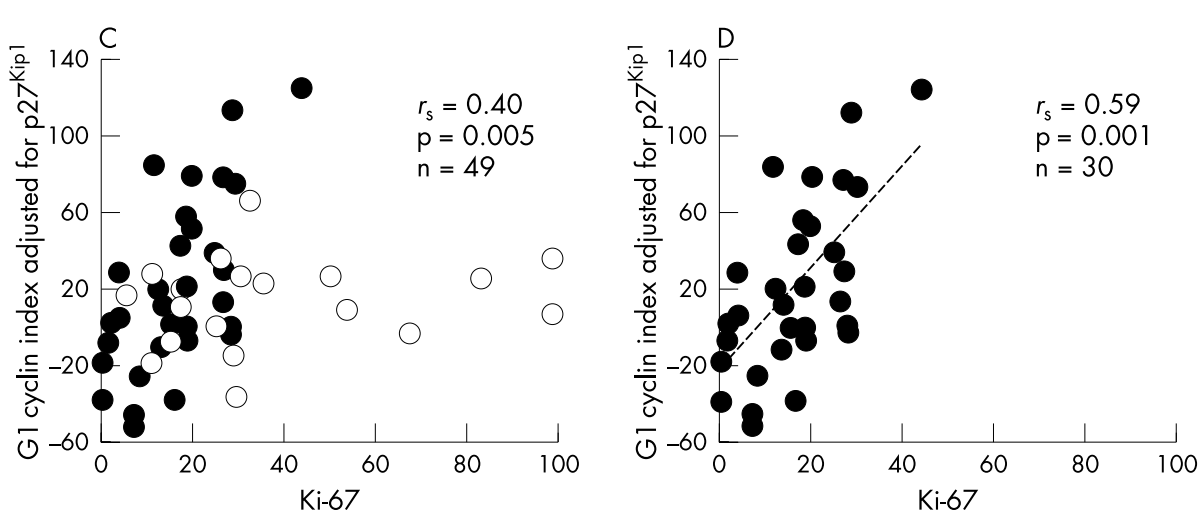

(D) even stronger positive correlation $\left(r_{s}\right.$, Spearman's rank correlation coefficient). Filled and unfilled circles represent superficial and muscle invasive tumours, respectively.

needed to verify this hypothesis in bladder cancer, although our data are consistent with the hypothesis that a cyclin Dl dependent pathway determines the evolution of a group of well differentiated low-stage papillary TCCs, whereas tumours that evolve via cyclin Dl independent mechanisms are less differentiated and pathologically more aggressive.

We examined the relation between the level of Gl cyclin expression and the proliferation index in superficial versus muscle invasive TCCs. Positive correlations were found between the levels of cyclin Dl and E expression and the proliferation index in superficial TCCs, but not in muscle invasive tumours. The ectopic expression of both cyclins D1 and $\mathrm{E}$ has been shown to have an additive effect on Gl phase progression. ${ }^{7}$ To assess whether there were any cooperative effects of the expression of both Gl cyclins on proliferation, we assessed a combined index of Gl cyclins, defined as the sum of their individual levels of expression. There was a significant positive correlation between the proliferation index and this combined index of Gl cyclin expression in superficial but not muscle invasive TCCs. The Gl cyclin index adjusted for p $27^{\text {Kipl }}$ expression was positively correlated with the proliferation index in all TCCs, but most strongly in the superficial group. Tumour proliferation in early stage TCC may be predominantly driven by the Gl cyclins, whereas in more advanced tumours, other proliferative mechanisms are involved. These observations are consistent with the reported accumulation of RB and TP53 mutations in advanced TCCs. ${ }^{29} 3435$ Moreover, Wright et al have reported that the Ki-67 proliferation indices for $\mathrm{pRb}$ negative and $\mathrm{p} 53$ positive TCCs are nearly twice those for $\mathrm{pRb}$ positive and $\mathrm{p} 53$ negative tumours. ${ }^{36}$

A positive relation between cyclin E expression and the proliferation index has been reported in several different tumour types. ${ }^{37-40}$ Our study found a negative correlation between high levels of cyclin E expression and the proliferation index. This correlation changed from positive to negative with increasing levels of cyclin E expression. Kamai et al suggested that cyclin E overexpression might be characteristic of a subset of bladder cancer, especially the early stages of invasion. ${ }^{40 a}$

$\mathrm{p} 27^{\mathrm{Kipl}}$ is a major negative regulator of cyclin E and can render it functionally inactive. ${ }^{1-3}$ High expressors versus low expressors of cyclin E had significantly higher levels of p27 Kip1 expression, and overall there was a positive correlation between p27 $7^{\text {Kipl }}$ and cyclin E expression. ${ }^{23}{ }^{41}$ Cyclin D1 can effectively sequester p27 $7^{\text {Kipl }}$ away from cyclin E-CDK2 complexes, ${ }^{3}{ }^{42}$ so that changes in the level of cyclin Dl can result in altered cyclin E associated kinase activity, without a corresponding change in p27 Kipl concentrations. There was no significant difference in the levels of cyclin Dl expression in high versus low expressors of cyclin E. As cyclin E expression reached high levels $(>40 \%)$, its association with the proliferation index changed from positive to negative, and this was accompanied by an increase in p $27^{\text {Kipl }}$ expression, with no significant change in cyclin D1. Taken together, these findings suggest that the inverse relation between cyclin $\mathrm{E}$ and the proliferation index in high expressors of cyclin E might be explained, at least in part, by a coordinate increase in p27 $27^{\text {Kipl }}$ mediated inhibition of cyclin E activity.

Our study supports the experimental data of Sgambato et al. ${ }^{43}$ They demonstrated that ectopic overexpression of cyclin E in the HCll mouse mammary epithelial cell line resulted in a prolonged Gl phase and a protracted G0-S transition, leading to growth inhibition. This was accompanied by increased p $27^{\mathrm{Kipl}}$ and decreased cyclin E associated kinase activity. They suggested a putative positive feedback loop between cyclin E and $\mathrm{p} 27^{\mathrm{Kipl}}$.

Del Pizzo and colleagues ${ }^{22}$ reported that in primary bladder TCC, $\geqslant 30 \%$ expression of cyclin E was associated with prolonged survival, whereas $<30 \%$ expression was associated with reduced survival. Our data suggest that the reported prognostic significance of cyclin E may be the result of its functional inactivation by the increasing amounts of p $27^{\text {Kipl }}$ seen in high expressors of cyclin E. In contrast, cyclin 


\section{Take home messages}

- Our findings suggest that cyclins D1 and E and p27 Kip1 play a role in the proliferation, differentiation, and progression of bladder transitional cell carcinomas (TCCs)

- Cyclins DI and E may cooperate in driving proliferation in the early stages of tumour progression

- Cyclin E may be important in bladder cancer progression

- These findings have implications for the development of novel therapeutic strategies targeting G1 phase cell cycle proteins in TCC

E is probably functionally active in low expressors, as demonstrated by a positive correlation between its level of expression and the proliferation index.

The relation between $\mathrm{p} 27^{\mathrm{Kipl}}$ expression and the proliferation index has not previously been studied in TCC. In normal cells, there is an inverse relation between p $27^{\mathrm{Kipl}}$ expression and the proliferation index. ${ }^{44}{ }^{45}$ However, in tumour cells this association is not always present. In breast ${ }^{46}$ and colorectal cancers, ${ }^{47}$ p $27^{\text {Kipl }}$ expression does not correlate with the proliferation index, whereas in some other tumours, an inverse association has been reported ${ }^{45} 48$ We found a weak but significant inverse relation between p27 $7^{\text {Kipl }}$ expression and proliferation index in primary bladder cancer. Moreover, similar to previous reports in some cancers, ${ }^{4144} 47$ we identified a subset of TCCs with high proliferation indices despite high level expression of $\mathrm{p} 27^{\mathrm{Kipl}}$. High concentrations of $\mathrm{p} 27^{\mathrm{Kipl}}$ are normally characteristic of quiescent cells, so it is not clear how these rapidly proliferating tumours tolerate this.

Concurrent expression of cyclins DI and E and the CDKI, $\mathrm{p} 27^{\mathrm{Kipl}}$, has not previously been reported in TCC. We have elucidated important interrelations between the expression of these proteins and the proliferation index that support a role for them in tumour proliferation, differentiation, and progression. Our results (1) indicate that cyclins Dl and E may cooperate in driving proliferation in the early stages of tumour progression; (2) suggest that cyclin E may be important in bladder cancer progression, despite the lack of a significant correlation between its level of expression and tumour grade or pathological stage; and (3) underscore the importance of studying cell cycle proteins concurrently rather than independently. These findings have implications for the development of novel therapeutic strategies targeting Gl phase cell cycle proteins in TCC.

\section{Authors' affiliations}

A A Khan, K S Chaudhary, Z Gulzar, G W H Stamp, E-N Lalani, Department of Histopathology, Imperial College, Hammersmith Hospital Campus, Du Cane Road, London W12 ONN, UK

P D Abel, Department of Surgery, Imperial College

\section{REFERENCES}

1 Cordon-Cardo C. Mutations of cell cycle regulators. Biological and clinical implications for human neoplasia. Am J Pathol 1995;147:545-60.

2 Hartwell LH, Kastan MB. Cell cycle control and cancer. Science 1994:266:1821-8.

3 Sherr CJ. Cancer cell cycles. Science 1996;274:1672-7.

4 Calbo J, Parreno M, Sotillo E, et al. Gl cyclin/cyclin-dependent kinasecoordinated phosphorylation of endogenous pocket proteins differentially regulates their interactions with E2F4 and E2F1 and gene expression. J Biol Chem 2002;277:50263-74

5 Resnitzky D, Gossen M, Bujard H, et al. Acceleration of the Gl/S phase transition by expression of cyclins DI and $\mathrm{E}$ with an inducible system. Mol Cell Biol 1994;14:1669-79.
6 Ohtsubo M, Theodoras AM, Schumacher J, et al. Human cyclin E, a nuclear protein essential for the G1-to-S phase transition. Mol Cell Biol 1995; 15:2612-24

7 Resnitzky D, Reed SI. Different roles for cyclins D1 and E in regulation of the G1-to-S transition. Mol Cell Biol 1995; 15:3463-9.

8 Lukas J, Bartkova J, Rohde M, et al. Cyclin D1 is dispensable for G1 control in retinoblastoma gene-deficient cells independently of cdk4 activity. Mol Cell Biol 1995; 15:2600-11.

9 Tam SW, Theodoras AM, Shay JW, et al. Differential expression and regulation of cyclin D1 protein in normal and tumor human cells: association with Cdk4 is required for cyclin DI function in G1 progression. Oncogene 1994;9:2663-74.

10 Lukas J, Herzinger T, Hansen K, et al. Cyclin E-induced S phase without activation of the pRb/E2F pathway. Genes Dev 1997;1 1:1479-92.

11 Donnellan R, Chetty R. Cyclin D1 and human neoplasia. Mol Pathol 1998;51:1-7.

12 Donnellan R, Chetty R. Cyclin E in human cancers. FASEB J 1999:13:773-80.

13 Kato JY, Matsuoka M, Polyak K, et al. Cyclic AMP-induced G1 phase arrest mediated by an inhibitor (p27Kip1) of cyclin-dependent kinase 4 activation. Cell 1994;79:487-96.

14 Toyoshima H, Hunter T. p27, a novel inhibitor of G1 cyclin-Cdk protein kinase activity, is related to p21. Cell 1994;78:67-74

15 Rivard N, L'Allemain G, Bartek J, et al. Abrogation of p27Kipl by cDNA antisense suppresses quiescence (G0 state) in fibroblasts. J Biol Chem 1996;271:18337-41.

16 Lloyd RV, Erickson LA, Jin L, et al. p27kip 1: a multifunctional cyclin-dependent kinase inhibitor with prognostic significance in human cancers. Am J Pathol 1999;154:313-23.

17 Lee CC, Yamamoto S, Morimura K, et al. Significance of cyclin D1 overexpression in transitional cell carcinomas of the urinary bladder and its correlation with histopathologic features. Cancer 1997;79:780-9.

18 Niehans GA, Kratzke RA, Froberg MK, et al. Gl checkpoint protein and p53 abnormalities occur in most invasive transitional cell carcinomas of the urinary bladder. Br J Cancer 1999:80:1175-84.

19 Shin KY, Kong G, Kim WS, et al. Overexpression of cyclin D1 correlates with early recurrence in superficial bladder cancers. Br J Cancer 1997;75: 1788-92.

20 Wagner U, Suess K, Luginbuhl T, et al. Cyclin D1 overexpression lacks prognostic significance in superficial urinary bladder cancer. J Pathol 1999; 188:44-50.

21 Sgambato A, Migaldi M, Faraglia B, et al. Loss of P27Kipl expression correlates with tumor grade and with reduced disease-free survival in primary superficial bladder cancers. Cancer Res 1999:59:3245-50.

22 Del Pizzo JJ, Borkowski A, Jacobs SC, et al. Loss of cell cycle regulators p27(Kip 1) and cyclin E in transitional cell carcinoma of the bladder correlates with tumor grade and patient survival. Am J Pathol 1999;155:1129-36.

23 Mostofi FK, Sobin HL, Torlini H. Typing of urinary bladder tumours. Geneva: World Health Organisation, 1973.

24 Fleming ID, Cooper JS, Henson DE, et al, eds. American Joint Committee on Cancer (AJCC) cancer staging manual, 5th ed. Philadelphia: Lippincott-Raven Publishers, 1997:241-3.

25 Dutta A, Chandra R, Leiter LM, et al. Cyclins as markers of tumor proliferation: immunocytochemical studies in breast cancer. Proc Natl Acad Sci U S A 1995;92:5386-90.

26 Keyomarsi K, Pardee AB. Redundant cyclin overexpression and gene amplification in breast cancer cells. Proc Natl Acad Sci U S A 1993;90:1112-16.

27 Lee CC, Yamamoto S, Wanibuchi H, et al. Cyclin Dl overexpression in rat two-stage bladder carcinogenesis and its relationship with oncogenes, tumor suppressor genes, and cell proliferation. Cancer Res 1997;57:4765-76.

28 Ogawa K, Kimoto N, Asamoto M, et al. Aberrant expression of p27(Kipl) is associated with malignant transformation of the rat urinary bladder epithelium. Carcinogenesis 2000;21:117-21.

29 Cordon-Cardo C, Zhang ZF, Dalbagni G, et al. Cooperative effects of p53 and $\mathrm{pRB}$ alterations in primary superficial bladder tumors. Cancer Res 1997;57:1217-21

30 Muller H, Lukas J, Schneider A, et al. Cyclin D1 expression is regulated by the retinoblastoma protein. Proc Natl Acad Sci U S A 1994:91:2945-9.

31 Jiang W, Zhang YJ, Kahn SM, et al. Altered expression of the cyclin D1 and retinoblastoma genes in human esophageal cancer. Proc Natl Acad Sci U S A 1993;90:9026-30.

32 Nielsen NH, Emdin SO, Cajander J, et al. Deregulation of cyclin E and D1 in breast cancer is associated with inactivation of the retinoblastoma protein. Oncogene 1997; 14:295-304.

33 Schaver IE, Siriwardana S, Langan TA, et al. Cyclin D1 overexpression vs. retinoblastoma inactivation: implications for growth control evasion in nonsmall cell and small cell lung cancer, Proc Natl Acad Sci U S A 1994;91:7827-31.

34 Cote RJ, Dunn MD, Chatterjee SJ, et al. Elevated and absent pRb expression is associated with bladder cancer progression and has cooperative effects with p53. Cancer Res 1998:58:1090-4.

35 Logothetis $\mathrm{CJ}, \mathrm{Xu} \mathrm{HJ}$, Ro JY, et al. Altered expression of retinoblastoma protein and known prognostic variables in locally advanced bladder cancer. J Natl Cancer Inst 1992;84:1256-61.

36 Wright $C$, Thomas $D$, Mellon K, et al. Expression of retinoblastoma gene product and p53 protein in bladder carcinoma: correlation with Ki67 index. Br J Urol 1995;75:173-9.

37 Ito $Y$, Matsuura N, Sakon $M$, et al. Expression and prognostic roles of the G1S modulators in hepatocellular carcinoma: p27 independently predicts the recurrence. Hepatology 1999;30:90-9. 
38 Kourea HP Cordon-Cardo C, Dudas M, et al. Expression of p27(kip) and other cell cycle regulators in malignant peripheral nerve sheath tumors and neurofibromas: the emerging role of p27(kip) in malignant transformation of neurofibromas. Am J Pathol 1999;155:1885-91.

39 Molendini L, Benassi MS, Magagnoli G, et al. Prognostic significance of cyclin expression in human osteosarcoma. Int $J$ Oncol 1998; 12:1007-11.

40 Yasui W, Kuniyasu H, Yokozaki H, et al. Expression of cyclin E in colorectal adenomas and adenocarcinomas: correlation with expression of $\mathrm{Ki}-67$ antigen and p53 protein. Virchows Arch 1996:429:13-9.

40a Kamai T, Takagi K, Asami H, et al. Decreasing p27 (Kipi) and cyclin E protein levels are associated with progression from superficial into invasive bladder cancer. Br J Cancer 2001:84:1242-51.

41 Sgambato A, Zhang YJ, Arber N, et al. Deregulated expression of p27(Kip1) in human breast cancers. Clin Cancer Res 1997:3:1879-87.

42 Reynisdottir I, Polyak K, lavarone A, et al. Kip/Cip and Ink4 Cdk inhibitors cooperate to induce cell cycle arrest in response to TGF-beta. Genes Dev 1995:9:1831-45.

43 Sgambato A, Han EK, Zhou $P$, et al. Overexpression of cyclin E in the $\mathrm{HCl} 1$ mouse mammary epithelial cell line is associated with growth inhibition and increased expression of p27(Kipl). Cancer Res 1996;56:1389-99.

44 Fredersdorf S, Burns J, Milne AM, et al. High level expression of p27(kipl) and cyclin D1 in some human breast cancer cells: inverse correlation between the expression of $\mathrm{p} 27(\mathrm{kipl})$ and degree of malignancy in human breast and colorectal cancers. Proc Natl Acad Sci U S A 1997;94:6380-5.

45 Lloyd RV, Jin L, Qian X, et al. Aberrant p27kipl expression in endocrine and other tumors. Am J Pathol 1997;150:401-7.

46 Tan P, Cady B, Wanner M, et al. The cell cycle inhibitor p27 is an independent prognostic marker in small (Tla,b) invasive breast carcinomas. Cancer Res 1997;57:1259-63.

47 Loda M, Cukor B, Tam SW, et al. Increased proteasome-dependent degradation of the cyclin-dependent kinase inhibitor p27 in aggressive colorectal carcinomas. Nat Med 1997;3:231-4.

48 Jordan RC, Bradley G, Slingerland J. Reduced levels of the cell-cycle inhibitor p27Kipl in epithelial dysplasia and carcinoma of the oral cavity. Am J Pathol 1998;152:585-90.

49 Sanchez-Beato M, Saez Al, Martinez-Montero JC, et al. Cyclin-dependent kinase inhibitor p27KIP1 in lymphoid tissue: p27KIP1 expression is inversely proportional to the proliferative index. Am J Pathol 1997;151:151-60.

\section{$\mathrm{ECHO}$}

DNA protein crosslinks and p53 expression are important in defining the danger of exposure to formaldehyde



Please visit the Molecular

Pathology website [www. molpath.com] for a link to the full text of this article.
D NA protein crosslinks (DPC) and mutation in the p53 tumour suppressor gene may be causally related and represent steps in the carcinogenicity of formaldehyde (FA). This has important implications for workers exposed to the latter.

Formaldehyde resins are used in producing adhesives for wood, plastics, textile, and leather while FA itself is a bactericide and tissue preservative. It is known to be a carcinogen; in vitro and in mammalian studies its primary genotoxic effect is the formation of DPC in target tissues but no studies on the latter had been conducted previously on humans.

The investigators examined DPC in peripheral blood mononuclear cells and p53 in serum from 186 workers in hospital laboratories ('exposed') and 213 hospital administrators ('controls').

DPC levels were significantly higher in the exposed group and the mean amount increased with increasing levels of exposure to FA, as determined by ambient air analysis. Additionally FA exposure increased the risk of having pantropic p53>150 pg/ml and mutant p53.

As FA undergoes exceptionally rapid biotransformation once absorbed there is no reliable direct biomarker. Thus, measuring DPC can be regarded as a surrogate for the dose of FA at critical target sites. The implications of this study are to provide a biologically plausible explanation for the epidemiological evidence of cancer risk from FA; and it may provide a method for screening exposed workers to identify those at higher risk.

A Occupational and Environmental Medicine 2003;60:403-409 